\title{
Blowing smoke: how cigarette manufacturers argued that nicotine is not addictive
}

"We show that the FDA is wrong on key factual and scientific points. Our comments review the many flaws in and evidence contradicting the FDA's allegations regarding such matters as tobacco growing, cigarette manufacturing and addiction."

Steven Parrish, senior vice president, Philip Morris. 2 January $1996{ }^{1}$

\section{Introduction}

Despite the release of secret documents showing that many tobacco industry scientists and officials have long considered nicotine to be addictive, ${ }^{2}$ some industry executives still insist that smoking is just a habit that should not be classified with other forms of drug dependency. ${ }^{3}$ In April 1999, cigarette manufacturer Brown \& Williamson unveiled a web site <www.brownandwilliamson.com> that contests the modern definition of addiction and argues that "the issue should be whether consumers are aware that smoking may be difficult to quit (which they are) and whether there is anything in cigarette smoke that impairs smokers from reaching and implementing a decision to quit (which we believe there is not)."

Such claims may confuse the general public and delay the enactment of effective tobacco control measures-especially those that take direct aim at nicotine addiction by regulating nicotine levels in tobacco products. ${ }^{4}$ Given the high level of public attention to nicotine, it is useful to review the scientific credibility of the industry's contention that nicotine is not addictive.

In January 1996, as volume III of their objections to proposed regulation by the United States Food and Drug Administration, cigarette manufacturers produced a 213-page brief primarily aimed "to address FDA's contention that nicotine has a significant effect on the structure or function of the body, including so-called nicotine addiction" ${ }^{5}$ (page 2 ). With scientific prose and 644 footnotes, the industry argued that nicotine is nothing more than a harmless ingredient present in tobacco products for flavour.

Although the FDA responded point by point to dozens of the industry's individual arguments in its final regulations, ${ }^{6}$ the purpose of this analysis is to elucidate six general unscientific techniques used by cigarette manufacturers to rebut the FDA's conclusion that nicotine is addictive.

The FDA's case for nicotine addiction The FDA found that nicotine met the major laboratory criteria for addiction set out by the United States surgeon general: psychoactive effects, controlled or compulsive use, and drug-reinforced behaviour. ${ }^{6}$ These criteria rely on several types of laboratory tests.

To demonstrate the psychoactive effects of nicotine, the agency noted that studies found that animals ${ }^{7}$ and humans ${ }^{8}$ could distinguish tiny doses of nicotine from placebo in "drug discrimination" tests, and that some former drug users mistook intravenous nicotine for cocaine in what are called "subjective effects" tests. ${ }^{9}$ To prove compulsive use and drug-reinforced behaviour, the agency cited research that animals ${ }^{10}$ and humans ${ }^{11}$ will compulsively dose themselves with nicotine in selfadministration studies. The FDA also noted that nicotine activates a key dopamine-based reward pathway in the brain associated with addictive behaviour. ${ }^{12}$

In addition to laboratory evidence of addiction, the FDA cited epidemiological evidence that smokers and consumers of smokeless tobacco met five clinical criteria of addiction developed by the American Psychiatric Association $^{13}$ : tolerance ${ }^{14}$; a characteristic withdrawal syndrome ${ }^{15}$; use of larger amounts than intended ${ }^{16}$; unsuccessful efforts to cut down ${ }^{17}$; and use despite problems. ${ }^{18}$

Overall, the FDA cited several surveys estimating an addiction rate of $77-92 \%$ among smokers. ${ }^{19-22}$

\section{The industry's response}

In volume III, cigarette manufacturers contended that the FDA used the wrong definition of addiction and misinterpreted numerous laboratory and clinical studies to reach an unjustified claim of jurisdiction. Manufacturers depended upon six unscientific techniques to cast doubt on the addictiveness of nicotine.

FALSE ASSUMPTIONS

A false assumption is an erroneous contention presented as fact. Volume III begins with the industry's assertion that the "traditional" definition of addiction is "intoxication, tolerance and a physical dependence that was manifested by withdrawal"5 (page 6). As smokers are not intoxicated, the industry argued, how would any reasonable person conclude that nicotine is addictive?

Yet the industry offered no source for this definition. As noted by the FDA, the World Health Organisation rejected the belief that intoxication is necessary for addiction in 1964, when the group recognised that opiate users often became tolerant to the drugs' psychological effects. ${ }^{23}$ Cigarette manufacturers had invented a definition of addiction from which to argue that nicotine is not addictive. 
A second false assumption in volume III was the industry's claim that "if smoking behavior were controlled entirely or even primarily, by nicotine's pharmacological effects, then providing nicotine to abstinent smokers should eliminate both their desire to smoke and any 'nicotine withdrawal' symptoms" (page 127). From this assumption, the industry argued that clinical trials of the nicotine patch and gum-which demonstrated a 12-month abstinence rate of only $20 \%$ ( $v$ 9\% for placebo $)^{24}$ - proved that nicotine did not play a key role in smoking behaviour.

In fact, if replacement therapy truly eliminates the desire to use a drug and all of its withdrawal symptoms, then methadone-the prototype of replacement therapy-would wean addicts from heroin without fail. But as addiction medicine specialists have long recognised, intravenous heroin and inhaled nicotine produce rapidly peaking levels of drugs and more addictive behaviour than oral methadone and the transcutaneous nicotine patch. ${ }^{25}$ In fact, the industry's point deserved to be turned on its head: if nicotine is only in cigarettes for taste, then why should studies of transdermal nicotine show any significant and sustained benefit, however small?

A third false assumption was the industry's claim that, as many smokers quit on their own, nicotine could not be addictive. But no scientific authority considers substances non-addictive just because some users quit on their own. Indeed, many heroin addicts become abstinent by themselves ${ }^{26}$ and more than three-quarters of recovered alcoholics in a recent survey achieved success without formal treatment. ${ }^{27}$

Fourth, the industry claimed that because smokers do not use "ever-increasing amounts to achieve a desired effect", nicotine does not induce tolerance ${ }^{5}$ (page 28). Yet persistent dose escalation is not the sine qua non of tolerance, and smokers often behave like many heroin addicts who maintain a constant dose for years. ${ }^{28}$ Acute tolerance to nicotine is demonstrated by physiological and subjective differences in response to cigarettes before and after a period of abstinence. ${ }^{29}$ Over a third of occasional users of cigarettes do escalate to daily use. ${ }^{30}$

The industry thus used false assumptions to deny widely accepted definitions of addiction, ${ }^{31-33}$ the scientific understanding of the limits of replacement therapy, ${ }^{34}$ and the meaning of tolerance. ${ }^{25}$

DIVIDE AND CONFUSE

A credible scientific review addresses the entirety of the evidence as well as its parts. But a second technique used by cigarette manufacturers in volume III does just the opposite, by focusing on the details to the exclusion of the bigger picture.

Using a "divide and confuse" technique, the industry argued in volume III that each individual laboratory test for addiction was not sufficient evidence ${ }^{5}$ (pages 30-40). The problem with self administration tests, according to cigarette manufacturers, was that "many commonly used substances and activities act as reinforcers." Drug discrimination tests were inadequate because "most substances that produce 'discriminative' stimulus effects are not addictive." Cigarette manufacturers noted that addiction expert Robert Balster is sceptical of relying on one test alone. But Balster went on to argue that national regulatory authorities should rely on laboratory studies of drug abuse potential in combination before approval of suspect drugs because they "play an important role in the prevention of drug abuse". He concluded that "the increased use of these methods should be encouraged." ${ }^{35}$ Indeed, the FDA had used the results of all these tests-each necessary and together sufficient - to show that nicotine meets all the laboratory criteria for addiction.

The industry also attempted to "divide and confuse" data on nicotine replacement therapy. Cigarette manufacturers devoted more than 40 pages in volume III to showing that some small clinical trials of nicotine gum, nasal spray, and patch failed to show statistically significant success in helping smokers quit. Yet the industry never acknowledged that published studies summarising the evidence, involving thousands of patients, demonstrate conclusively that nicotine replacement works. ${ }^{36} 37$

\section{COMMON NONSENSE}

A scientist understands that each experiment has its own limited scope and goals. But in volume III, cigarette manufacturers criticised key laboratory studies using "common sense" arguments that ignored the purpose and methods of the investigations.

For example, in response to a key study cited by the $\mathrm{FDA}^{9}$ demonstrating that former drug addicts reported psychoactive changes of nicotine, the industry argued that "obviously, whatever the subjective effects reported by this group, they do not represent a true measure of nicotine's subjective effects in the general population" (page 45). Yet that was never the purpose of the study. As originally designed by the National Institute on Drug Abuse, a subjective effects assay must use former addicts as subjects, as unexposed subjects frequently have initial aversive reactions to addictive drugs. ${ }^{38}$ In the study cited by the FDA, subjects identified intravenous nicotine as cocaine, a finding that is only possible because the subjects had used cocaine previously.

Another example of "common nonsense" can be found in the industry's response to a study in which subjects recognised very small doses of nicotine in inhaled nasal spray, ${ }^{39}$ thus proving that nicotine serves as a "discriminative stimulus". Cigarette manufacturers responded that male subjects only identified $50 \%$ of test doses of $2 \mu \mathrm{g} / \mathrm{kg}$ correctly, arguing: "A fifty percent response . . . is exactly what would be predicted by random chance. Such weak data do not prove that nicotine has 'discriminative stimulus' effects" ${ }^{5}$ (pages 42-3).

The industry's claim misinterpreted the study, which was designed to determine 
whether a dose of $12 \mu \mathrm{g} / \mathrm{kg}$ (less than one cigarette) could be identified by subjects. Every subject did so successfully. The researchers then lowered the dose to find the level that could not be differentiated from placebo-the standard practice for this kind of experiment. That lower dose then became the basis of the industry's argument.

Other examples of common nonsense included the industry's claim that no-nicotine cigarettes cause subjects to report subjective feelings of euphoria. So how could nicotine be responsible for the satisfaction of cigarettes? In the study in question, researchers gave no-nicotine cigarettes to smokers in withdrawal. ${ }^{40}$ The smokers' euphoria from nicotine had been conditioned to the act of smoking. It is well known to addiction specialists that saline injections to heroin addicts replicate euphoria for a period of time. ${ }^{41}$ This study confirmed a similar phenomenon for nicotine.

Similarly, the industry objected ${ }^{5}$ (page 35 ) to a key self administration study of nicotine in squirrel monkeys ${ }^{42}$ because the animals had to be trained to give themselves nicotine with visual cues-implying that the visual cues were responsible for the self administration. But the industry ignored the paper's main finding: monkeys readily gave themselves nicotine with visual cues, but did not do the same with placebo and visual cues.

With "common nonsense", the industry tried to obscure a key FDA finding, well appreciated by the scientific community-nicotine meets the same laboratory tests for addiction as other addictive drugs. ${ }^{43}$

THE HEDGE HUNT

As soon as a scientific discovery is made, questions arise about the validity of the findings and need for further investigation; scepticism is part of the scientific process. In volume III, cigarette manufacturers based major arguments on these appropriate scientific hedges, treating them as proven contentions.

For example, the industry cited a study in which the authors concluded that "we have encouraged caution in what is made of what smokers say about their wish to give up smoking", ${ }^{44}$ as proving that polls of smokers are "invalid" and the statistic of smokers who want to quit "means nothing" (page 91). Similarly, referring to addiction researcher Jerome Jaffe's observation that "several aspects of the tobacco withdrawal syndrome are not yet fully explained," 25 the industry concluded that "the so-called tobacco (or nicotine) withdrawal syndrome is not the result of nicotine 'withdrawal"'5 (page 26).

By amplifying these hedges, the industry inappropriately questioned such key facts of nicotine addiction as most smokers want to quit, ${ }^{45}$ and nicotine abstinence causes a significant withdrawal syndrome. ${ }^{15}$

SPECULATION AS EVIDENCE

An integral part of science is hypothesis; researchers generate theories that can be proven by subsequent investigation. No scientist, however, would treat such hypothesis as fact without confirmatory evidence. But in volume III, the industry equated hypothesis with proof to argue the innocuousness of nicotine.

One example is the industry's response to the FDA's citation of research linking nicotine to the dopamine-based reward pathway of the brain. Stimulation of this pathway by such substances as cocaine, heroin, and nicotine causes animals to seek out and repeat the cause of the stimulation. ${ }^{46}$ Increased dopamine levels in the system have been measured following nicotine administration. ${ }^{12}$ The tobacco industry responded in volume III that nicotine's effects cannot be significant because dopamine release is caused by such common exposures as magnetic fields ${ }^{5}$ (page 59).

In the sole paper cited by the industry to make this argument, ${ }^{47}$ researchers treated two patients with magnetic fields (with no control group). The first patient was a young woman with multiple sclerosis and the other an elderly man with Parkinson's disease. In neither case did researchers measure any substances, or image any part of the brain. They did make several clinical observations. For the woman: "Magnetic fields were applied for 6 minutes ... [with] marked elevation of mood and level of energy, change in the 'perception of reality', intense sexual arousal and an unusual craving for food (specifically for salty foods) and cigarette smoking." The second also experienced immediate euphoria and sexual arousal, and after the experiment installed a magnetic field in his home.

These researchers concluded: "We propose, therefore, that the behavioral and mental effects of treatment with magnetic fields may be mediated via [rapid eye movement sleep deprivation] and, by inference, involve activation of limbic dopaminergic reward sites." This speculation served as the industry's evidence.

MISUSE OF STATISTICS

In volume III, the tobacco industry failed to present statistics fairly and accurately. For example, in response to a key study showing $90 \%$ of self reported smokers are addicted to cigarettes, the industry argued ${ }^{5}$ (page 75): (a) mean cigarette consumption in this study ${ }^{19}$ was 28 per day; (b) $22 \%$ of smokers in another (unpublished) survey smoked more than 25 cigarettes a day; and therefore (c) the 90\% addicted figure applies to "at most, 22 percent of smokers." This led the industry to imply that even by the FDA's definition, only $20 \%(90 \%$ of $22 \%$ ) of smokers are addicted.

In making this argument, however, the industry treated 28 cigarettes as the minimum (not mean) consumption in the first study. If $90 \%$ of smokers who consumed at least 28 cigarettes a day were addicted, then one might appropriately compare the population with just $22 \%$ of the second survey. But as the smokers in the first survey consumed a mean of 28 cigarettes, many of them must have smoked less. The industry's conclusion was statistically invalid. With such distortion the industry 
attempted to undermine several studies that all revealed a high rate of nicotine addiction. ${ }^{19-22}$

\section{Conclusion}

In volume III, cigarette manufacturers took advantage of the scientific process-the complexity of laboratory studies, hypotheses, theory and statistics - to reach a conclusion contrary to that of every relevant world scientific authority. Previous investigations have demonstrated how the industry supports poor quality research on environmental tobacco smoke. ${ }^{48}$ As nicotine occupies centre stage in regulatory battles over tobacco, the public should be aware of the deceptive techniques and substandard science underlying the industry's claim that nicotine is not addictive.

The author would like to thank Stanton Glantz and Robert Kahn for reviewing drafts and suggesting editorial revisions to this manuscript, Yngvild Olsen for editing and proof reading, this manuscript, Yngvild Olsen for editing and proof reading, issues. Presented in part at the American Public Health issues. Presented in part at the Americ
Association conference, November 1997.

JOSHUA SHARFSTEIN

Department of Pediatrics, Boston Medical Center, Boston, Massachusetts, USA;

joshs@bu.edu

1 Parrish S. Tobacco industry's comments on the FDA proposed regulation of tobacco products. Federal Docuproposed regulation of tobacco products. Federal Docu

2 Glantz SA, Slade J, Bero LA, et al. The cigarette papers. Berkeley, California: University of California Press, 1996.

3 Mishra R. Tobacco executives refuse to call nicotine addictive. New Orleans Times-Picayune 1998 February 10:A4.

4 Douglas C. Taking aim at the bull's eye: the nicotine in tobacco products. Tobacco Control 1998:7:215-18.

5 Brown \& Williamson Tobacco Corp.; Liggett Group, Inc.; Lorillard Tobacco Co.; Philip Morris Inc.; RJ Reynolds Tobacco Co.; Tobacco Institute, Inc. Comments before the United States Food and Drug Administration. Docket No 95N-0253 and 95N-0253J, vol III, January 1996.

6 US Food and Drug Administration. Nicotine in cigarettes and smokeless tobacco is a drug and these products are nicotine delivery devices under the Federal Food, Drug and Cosmetic Act: jurisdictional determination. Federal Register 1996;61:44690-846.

7 Morrison CF, Stephenson JA. Nicotine injections as the Morrison CF, Stephenson JA. Nicotine injections as the
conditioned stimulus in discrimination learning. Psychopconditioned stimulus in discrimi

8 Kallman WM, Kallman MJ, Harry GJ, et al. Nicotine as a discriminative stimulus in human subjects. In: Colpaert FC, Slangen JL, eds. Drug discrimination: applications in CNS pharmacology. Amsterdam: Elsevier Biomedical, 1982:211-18.

9 Henningfield JE, Miyasato K, Jasinski DR. Abuse liability and pharmacodynamic characteristics of intravenous and inhaled nicotine. F Pharmacol Exp Ther 1985;234:1-12.

10 Spealman RD, Goldberg SR. Maintenance of scheduledcontrolled behavior by intravenous injections of nicotine in squirrel monkeys. F Pharmacol Exp Ther 1982;223:402-8.

11 Henningfield JE, Miyasoto K, Jasinski DR. Cigarette smokers self-administer intravenous nicotine. Pharmacol Biochem Behav 1983;19:887-90.

12 Pontiere FE, Tanda G, Orzi F, et al. Effects of nicotine on the nucleus accumbens and similarity to those of addictive drugs. Nature 1996;382:255-7.

13 American Psychiatric Association. Diagnostic and statistical manual of mental disorders. 4th ed. Washington, DC: APA, manual
1994.

14 Perkins KA, Grobe JE, Epstein LH, et al. Chronic and acute tolerance to subjective effects of nicotine. Pharmaco Biochem Behav 1993;45:375-81.

15 Hughes JR, Hatsukami D. Signs and symptoms of tobacco withdrawal, Arch Gen Psychiatr 1986;43:289-94.

16 Elders MJ, Perry CL, Erickson MP, et al. The report of the Surgeon General: preventing tobacco use among young people. Am 7 Public Health 1994;84:543-7.

17 US Centers for Disease Control and Prevention. Smoking cessation during previous year among adults-United States, 1990 and 1991. MMWR 1993;42:504-7.

18 Gallup GH. Smoking prevalence, beliefs, and activities by gender and other demographic indicators. Princeton, New Jersey: Gallup Organization, 1993.

19 Hughes JR, Gust SW, Pechacek TF. Prevalence of tobacco dependence and withdrawal. Am $\mathcal{f}$ Psychiatr 1987; 144:205-8.

20 Cottler L. Comparing DSM-III-R and ICD-10 substance use disorders. Addiction 1993;88:689-96.
21 Woody GE, Cottler LB, Cacciola J. Severity of dependence: data from the DSM-IV field trials. Addiction 1993; 88:1573-9.

22 Hale KL, Hughes JR, Oliveto $\mathrm{AH}$, et al. Nicotine dependence in a population-based sample. In: Problems of drug dependence. NIDA research monograph 132. Washington DC: Government Printing Office, 1993.

23 WHO Expert Committee on Addiction-Producing Drugs. WHO 1964. World Health Organisation technical report series No 273, 13th report. Geneva, Switzerland: World Health Organisation, 1964:3-20.

24 US Food and Drug Administration. Background on nicotine pharmacology. Appendix 1 to furisdictional analysis. Washington, DC: FDA, 1995:79.

25 Jaffe JH. Tobacco smoking and nicotine dependence. In: Nicotine psychopharmacology. Oxford: Oxford University Press, 1990:1-29.

26 Anglin $\mathrm{MD}$, Brecht ML, Woodward JA, et al. An empirical study for maturing out: conditional factors. Int $\mathcal{F}$ Addict $1986 ; 21: 233-46$

27 Sobell LC, Cunningham JA. Sobell MB. Recovery from alcohol problems with and without treatment: prevalence in two population surveys. Am f Public Health 1996; in two po $966-72$.

28 Jaffe JH. Drug addiction and drug abuse. In: Goodman and Gilman's The pharmacological basis of therapeutics, 8th ed. New York, New York: Pergamon, 1990:522-73.

29 West RJ, Russell MA. Cardiovascular and subjective effects of smoking before and after $24 \mathrm{~h}$ of abstinence from cigarettes. Psychopharmacology 1987;92:118-21.

30 Henningfield JE, Cohen C, Slade JD. Is nicotine more addictive than cocaine? Brf Addict 1991;86:565-9.

31 Royal Society of Canada. Tobacco, nicotine, and addiction: a committee report. Toronto, Canada: Health Protection Branch, Health and Welfare Canada, 1989:v-vi.

32 World Health Organisation. The ICD-10 classification of mental and behavioural disorders: clinical descriptions and diagnostic guidelines. Geneva, Switzerland: WHO, 1992:76.

33 UK Medical Research Council. The basis of drug dependence. MRC field review. London: Medical Research Council, 1994:11.

34 Jaskinski DR, Henningfield JE. Conceptual basis of replacement therapies for chemical dependence. In: Pomerleau $\mathrm{OF}$, Pomerleau CS, Fagerstrom KO, et al, eds. Nicotine replacement: a critical evaluation. New York, New York: Alan Liss, 1998:13-34.

35 Balster RL. Drug abuse potential evaluation in animals. $\mathrm{Br} \mathcal{F}$ Addict 1991;86:1549-88.

36 Fiore MC, Smith SS, Jorenby DE, et al. The effectiveness of the nicotine patch for smoking cessation: a meta-analysis. FAMA 1994;271:1940-7.

37 Tang JL, Law M. Wald N. How effective is nicotine replacement therapy in helping people to stop smoking? BMf 1994;308:21-6.

38 Jasinski DR, Henningfield JE. Human abuse liability assessment by measurement of subjective and physiological effects. In: Fischman MW, Mello NK, eds. Testing for abuse liability of drugs in humans. NIDA research monograph 92. Rockville Maryland: National Institute on Drug Abuse, 1989.

39 Perkins K, Grobe J, Scierka A, et al. Discriminative stimulus effects of nicotine in smokers. In: Clarke PBS, Quik M, Thurau K, et al, eds. International symposium on nicotine: the effects of nicotine on biological systems II. (Basel: Birkhauser Verlag, 1994), 111.

40 Butschky MF, Bailey D, Henningfield JE, et al. Smoking without nicotine delivery decreases withdrawal in 12-hour abstinent smokers. Pharmacol Biochem Behav 1995;50:91-

41 O'Brien CP, Testa T, Ternes J, et al. Conditioning effects of narcotics in humans. In: Behavioral tolerance: research and treatment implications. NIDA research monograph 18. (No 017-024-00899-8.) Washington, DC: Government Printing Office, 1978:67-71.

42 Goldberg SR, Spealman RD, Goldberg DM. Persistent behavior at high rates maintained by intravenous selfadministration of nicotine. Science 1981;214:573-5.

43 US Department of Health and Human Services. The health consequences of smoking: nicotine addiction. A report of the Surgeon General, 1988. Rockville, Maryland: Public Health Service, Centers for Disease Control, Office on Smoking and Health, 1988. (DHHS Publication No (CDC) 88-8406.)

44 Kozlowski LT, Herman CP, Frecker RC, What researchers make of what cigarette smokers say: filtering smokers' hot air. Lancet 1980;1 (8170):699-700.

45 US Centers for Disease Control and Prevention. Cigarette smoking among adults-United States, 1993. MMWR 1994:927.

46 Gold MS. Clinical implications of the neurobiology of addiction. In: Principles of addiction medicine. Chevy Chase, Maryland: American Society of Addiction Medicine, 1994.

47 Sandyk R, Tsagas N, Anninos PA, et al. Magnetic fields mimic the behavioral effects of REM sleep deprivation in humans. Int 7 Neurosci 1992;65:61-8.

48 Barnes DE, Bero LA. Industry-funded research and conflict of interest: an analysis of research sponsored by the tobacco industry through the Center for Indoor Air Research. F Health Polit Policy Law 1996:21:515-42. 